\title{
Hyperbranched polyester polyol plasticized tapioca starch/low density polyethylene blends
}

\author{
Manuel Guzmán', Diego Giraldo and Edwin Murillo²* \\ ${ }^{1}$ Grupo de Materiales Polímericos de Ingeniería, Universidad de Antioquia, Medellín, Colombia \\ ${ }^{2}$ Grupo de Investigación en Materiales Poliméricos - GIMAPOL, Departamento de Química, \\ Universidad Francisco de Paula Santander, San José de Cúcuta, Colombia \\ *edwinalbertomurillo@gmail.com
}

\begin{abstract}
In this work, low density polyethylene (LDPE)/plasticized starch (TPS) blends were prepared. The TPS employed in this study was obtained by plasticization of tapioca starch with a hyperbranched polyester polyol. Differential scanning calorimetry analysis showed that the melting temperature increased with the TPS content. The opposite effect was exhibited in the crystallization temperature and additional changes were not observed during the heating. X-ray diffraction analysis showed a reduction in intensity of the peak at Bragg's angle $17.5^{\circ}$, proving a diminution on A type crystallinity with the increasing amount of LDPE. Micrographs obtained by scanning electron microscopy exhibited starch granules without destructure. TPS acted as a filler to LDPE, since the mechanical properties (Young's modulus and tensile strength) improved ostensibly. The Young' modulus and tensile strength decreased with the amount of LDPE, however, the elongation at break exhibited an opposite behavior.
\end{abstract}

Keywords: LDPE, thermoplastic starch, blends, properties.

\section{Introduction}

Starch is a natural carbohydrate accumulated by green plants in the form of granules. It is composed of linear polysaccharide molecules (amylose) and branched molecules (amylopectin) $)^{[1]}$. The starch plasticization has spurred considerable interest in the last years. The starch presents a great importance as substrate due to wide availability, its low cost and its renewable character ${ }^{[2]}$. The investigation of new plasticizers constitutes a major topic in this context. The main plasticizer employed in the plasticization process of starch is glycerol ${ }^{[3]}$, but several other compounds such as urea ${ }^{[4]}$, ethanolamine ${ }^{[4]}$ and sorbitol ${ }^{[5]}$ have also been employed.

The hyperbranched polyester polyols (HBP) could be an alternative to plasticization process of starch due to the low viscosity it has in the molten and solution state, as well as its high number of $\mathrm{OH}$ groups and small hydrodynamic dimensions ${ }^{[6-9]}$.

Low density polyethylene (LDPE) is a polymer of the largest tonnage of consumption in the world. LDPE has excellent mechanical properties and it is employed mainly in packaging industry ${ }^{[10,11]}$. This polymer is derived from petrochemical sources and it is not biodegradable. In order to reduce the dependence on the depleting petrochemical resources, this material was blended with biopolymers such as starch $^{[12]}$. LDPE/starch blends are not compatible because LDPE has no polar groups that could interact with starch. However, TPS has been the target of research due to its low cost and ability to be modified or blended with other polymers in order to improve their properties and processing ${ }^{[13]}$. Furthermore, TPS blends allow for obtaining the biodegradable or partially biodegradable materials, which is the reason for the preparation of LDPE/starch blends.

Blends of recycled LDPE with starch would have two environmental advantages: the substitute of the virgin synthetic thermoplastic matrix by post-consumer materials, and the end products that would be biodegradable and cheap ${ }^{[14]}$.

LDPE/starch blends have been prepared from a dispersion of starch granules in a LDPE matrix. Such blend, without a starch plasticizer, exhibits poor physico-chemical properties, even with only $10 \%$ of granulated $\operatorname{starch}^{[1]}$. St-Pierre et al. ${ }^{[12]}$ analyzed the performance of mixtures of TPS (using glycerol as a plasticizer) in a LDPE matrix. Plasticization process was carried out in a single-screw extruder with gas removal, connected to a twin-screw extruder, where finally the components of the mixture were blended.

Ning et al. ${ }^{[15]}$ studied the effect of citric acid on the properties of glycerol/starch/linear low-density polyethylene blends. The presence of citric acid (CA) improved the dispersion and plasticization of starch. The rheological study proved that CA could decrease the viscosity and improve the fluidity of the blends. The blends exhibited poor interfacial adhesion and the mechanical properties of the blends without CA were very poor. The tensile strength and the elongation at break were greatly enhanced in the presence of CA.

Pedroso and Rosa ${ }^{[14]}$ prepared recycled LDPE/corn starch blends, the proportions of starch in the blends were 30,40 and $50 \mathrm{wt} \%$. The addition of starch to LDPE decreased melt flow index (MFI) values, tensile strength and elongation at break. This behavior was the same as showed by virgin LDPE/corn starch blends. The melting and crystallization temperatures of the blends were the same as those of pure polymers. 
Garg and Jana ${ }^{[16]}$ evaluated the properties of LDPE/starch films using crosslinked and glycerol modified starch. The tensile strength, elongation and MFI of the films containing crosslinked starch were higher than those containing native starch, but the burst strength showed an opposite trend. For native starch modified with glycerol, the elongation and melt flow index of the films increased.

Rodriguez-Gonzalez et al. ${ }^{[1]}$ studied the effect of processing and glycerol content on the morphology and properties of LDPE/starch blends. Different types of commercial LDPE were used in the study. Micrographs showed that by using $27.5 \%$ or higher glycerol content and the high viscosity LDPE it was possible to break the granular structure of starch. It should be noted that granular structure of starch is preserved at low levels of glycerol and that granules act as filler ${ }^{[1]}$.

Guzmán and Murillo ${ }^{[17]}$ prepared blends of maleic-anhydride (MA)-grafted polyethylene (LDPE-g-MA) and starch plasticized with a hyperbranched polyester - HBP (TPS) employing proportions of 20/80,30/70, 40/60 and 50/50. They observed that HBP acted as a plasticizer for starch and the LDPE- $g$-MA/TPS blends, and that the A-type crystallinity of the starch was reduced. The thermal stability of the blends showed no significant changes regarding those of neat LDPE- $g$-MA and TPS. The viscosity of the blends was reduced with increasing shear rate and starch granules were observed by scanning electron microscopy. Furthermore, the tensile testing of the blends with increasing content of LDPE-g-MA showed a reduction in the tensile modulus and tensile strength, and an augment in the elongation at break.

According to the reviewed literature, there has been no report on the studies of the blends of LDPE and starch plasticized with a HBP (TPS) with an exception of LDPE- $g$-MA/TPS blends ${ }^{[17]}$. Therefore, the goal of this study was to prepare LDPE/TPS blends and evaluate the influence of the proportions of LDPE and TPS on the structural, thermal, rheological, morphological, and mechanical properties of all materials prepared. Further goal was to compare the properties of the LDPE/TPS blends prepared with those of the LDPE- $g$-MA/TPS blends ${ }^{[17]}$.

\section{Experimental Section}

\subsection{Materials}

In a previous study, TPS was prepared from tapioca starch $(60 \% \mathrm{wt})$ and HBP. The composition of starch was $17 \mathrm{wt} \%$ of amylose and $83 \mathrm{wt} \%$ of amylopectin. HBP was of the fourth generation, prepared from pentaerythritol and 2,2-bis(methylol)propionic acid ${ }^{[6-8]}$. The structural, thermal, rheological, morphological and mechanical properties of the TPS have been reported earlier ${ }^{[17]}$. LDPE 132I was supplied by Dow Plastics. This material has a density of $0.921 \mathrm{~g} / \mathrm{cm}^{3}$ and melt flow index of $0.22 \mathrm{~g} / 10 \mathrm{~min}$, whereas the thermal properties determined by DSC and TGA are as follows: melting temperature $\left(\mathrm{T}_{\mathrm{m}}\right) 114.1{ }^{\circ} \mathrm{C}$, melting enthalpy $\left(\Delta \mathrm{H}_{\mathrm{m}}\right) 91.5 \mathrm{~J} / \mathrm{g}$, crystallization temperature $(\mathrm{T})$ $89.8^{\circ} \mathrm{C}$, and decomposition temperature $\left(\mathrm{T}_{\mathrm{d}}\right) 469.7^{\circ} \mathrm{C}^{[11]}$.

\subsection{Preparation of the blends}

LDPE and TPS were mixed before to be added to the torque rheometer. Mixtures of LDPE with TPS were prepared using a Thermo Scientific torque rheometer at a temperature of $150{ }^{\circ} \mathrm{C}$ at $50 \mathrm{rpm}$ and a residence time of 6 minutes. The proportions of LDPE and TPS are given in Table 1.

\subsection{Characterization of the blends}

For IR analysis, films of the blends were analyzed on a FTIR spectrometer Spectrum One (Perkin Elmer) in the spectral range between 500 and $4000 \mathrm{~cm}^{-1}$ performing 8 scans. The thermal transitions of the materials were determined by differential scanning calorimetry (DSC) using a TA Instruments Q-100 with a heating rate of $10^{\circ} \mathrm{C} / \mathrm{min}$ in the temperature range from 0 to $200^{\circ} \mathrm{C}$. Thermogravimetric analysis (TGA) was performed to analyze the thermal stability of the samples. These measurements were performed on a TA Instruments Q-500 at a heating rate of $10{ }^{\circ} \mathrm{C} / \mathrm{min}$ in the temperature range from 50 to $550{ }^{\circ} \mathrm{C}$. The $\mathrm{X}$-ray diffraction (XRD) was performed with the purpose to identify crystalline forms present in the LDPE/TPS blends. Diffractograms were obtained on a PANalytical X'Pert PRO MPD diffractometer using $\mathrm{Cu}-\mathrm{K}$ alpha radiation ( $\lambda=1.5406 \mathrm{~A}$ ). The voltage and the operating current were $45 \mathrm{KV}$ and $40 \mathrm{~ms}$, respectively. The diffractograms were measured in the range of Bragg angle (20) from $10^{\circ}$ to $30^{\circ}$. The scanning electronic microscopy (SEM) analysis of fractured surfaces of the compounds was executed on a scanning electron microscope JEOL JSM-6490LV. SEM was used with a beam acceleration voltage of 10 to $20 \mathrm{kV}$. The rheological analyzes were performed on a Malvern Kinexus rotational rheometer using a plate-plate geometry of $20 \mathrm{~mm}$ at a controlled temperature of $130^{\circ} \mathrm{C}$ under static and dynamic conditions. The static analysis was performed in a static mode at shear rates from 0.01 to $1000 \mathrm{~s}^{-1}$. The rheological parameter recorded was the apparent viscosity $(\eta)$. The dynamic mode was used for characterizing the viscoelastic behavior of the samples. Frequency sweeps were performed from 0.1 to $100 \mathrm{~Hz}$ to a value of $0.2 \%$ strain. For tensile tests, the IV type test specimens were obtained with a piston-cylinder injecting machine at $150^{\circ} \mathrm{C}$ and a residence time of 4 minutes, employing a pressure of 75 Psi. Tensile tests were conducted under the standard ASTM D 638 at a rate of $5 \mathrm{~mm} / \mathrm{min}$ until the specimen failed.

\section{Results and Discussion}

Figure 1 presents the behavior of the materials during torque rheometry. The torque behavior with respect to the time is shown in Figure 1a.

Table 1. Proportions of LDPE and TPS of the blends.

\begin{tabular}{ccc}
\hline $\begin{array}{c}\text { LDPE/TPS } \\
\text { Blend }\end{array}$ & $\begin{array}{c}\text { LDPE } \\
(\mathbf{w t} \%)\end{array}$ & $\begin{array}{c}\text { TPS } \\
(\mathbf{w t} \%)\end{array}$ \\
\hline $20 / 80$ & 20 & 80 \\
$30 / 70$ & 30 & 70 \\
$40 / 60$ & 40 & 60 \\
$50 / 50$ & 50 & 50 \\
\hline
\end{tabular}



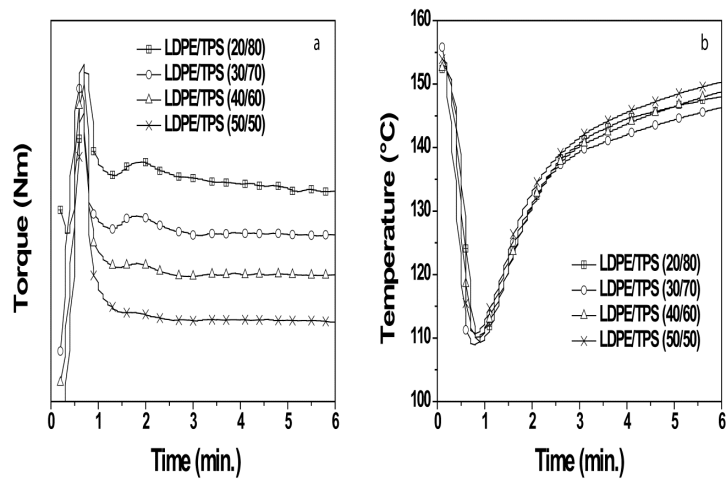

Figure 1. Torque rheometry of the blends: (a) torque vs time; and (b) temperatures vs time.

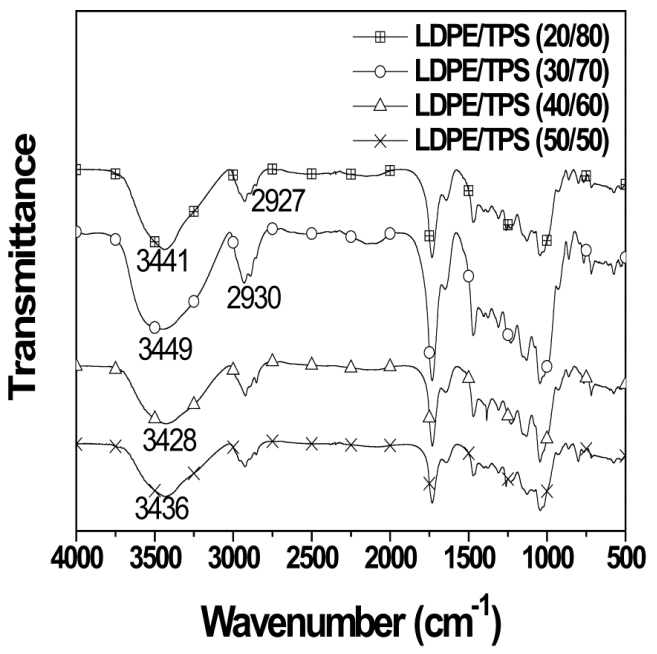

Figure 2. IR spectra of the LDPE/TPS blends.
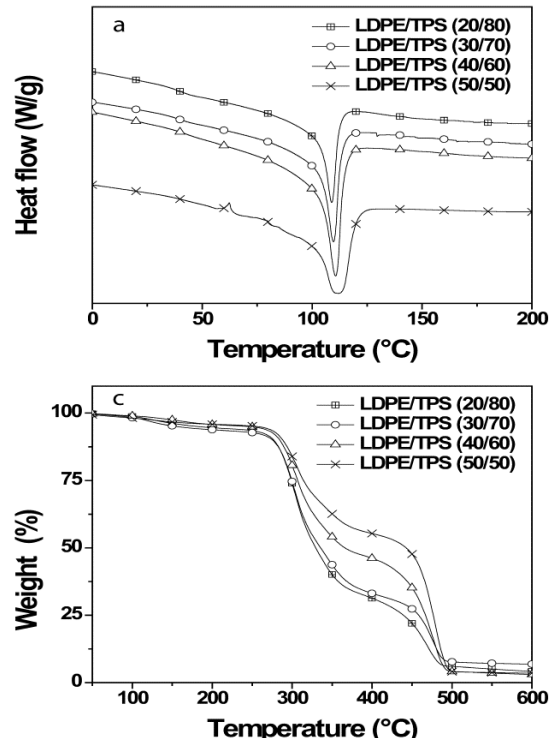

Torque of all the mixtures increased to a maximum value of $80 \mathrm{Nm}$ in the first minute. When the mixture was completely melted, the torque remained constant at $13 \mathrm{Nm}$ (Figure 1a). The temperature of the mixtures was also recorded (Figure 1b), however, notable differences between the blends were not observed. Due to heat transfer effects (melting process), the temperature was reduced to about $110{ }^{\circ} \mathrm{C}$ and then increased until the sample was melted. The same behavior was observed for LDPE- $g$-MA/TPS blends ${ }^{[17]}$.

Figure 2 shows the IR spectra of the LDPE/TPS blends. The signal that appears at $3439 \mathrm{~cm}^{-1}$ is assigned to stretching of $\mathrm{OH}$ groups (intramolecular and intermolecular bonding); this peak appears at lower frequency than that of the TPS $\left(3355 \mathrm{~cm}^{-1}\right)^{[17]}$. This was due to structural rearrangement or new interactions that occurred during the blend preparation. The same was observed for LDPE- $g$-MA/TPS blends ${ }^{[17]}$.

The signal about $2900 \mathrm{~cm}^{-1}$ is due to $-\mathrm{CH}_{2}$ stretching and the signal at $1650 \mathrm{~cm}^{-1}$ is assigned to bending of $\mathrm{OH}$ groups of water. The signal around $1470 \mathrm{~cm}^{-1}$ is attributed to angular deformation of $-\mathrm{CH}_{2}$ A signal appears at $1309 \mathrm{~cm}^{-1}$, which corresponds to $\mathrm{C}-\mathrm{O}$ bending of ester groups belonging to HBP in TPS. The signals that appear at 1125 and $1140 \mathrm{~cm}^{-1}$ are due to $\mathrm{C}-\mathrm{O}$ and $\mathrm{C}-\mathrm{OH}$ stretching, respectively. The signal at $1010 \mathrm{~cm}^{-1}$ is attributed to $\mathrm{C}-\mathrm{O}$ bond stretching of C-O-C groups in the anhydroglucose ring. The signal at $720 \mathrm{~cm}^{-1}$ is due to methylene rocking ${ }^{[8]}$ and is characteristic of $\mathrm{LDPE}^{[11]}$. The signals that belong to $\mathrm{C}-\mathrm{O}$ and $\mathrm{C}-\mathrm{OH}$ bonds also appear in the spectra of TPS and LDPE-g-MA/TPS blends ${ }^{[17]}$.

Figure 3 shows the DSC (Figures $3 \mathrm{a}$ and $3 \mathrm{~b}$ ) and TGA (Figures $3 \mathrm{c}$ and $3 \mathrm{~d}$ ) thermograms of the samples. Despite the fact that TPS exhibits the glass transition temperature $\left(\mathrm{T}_{\mathrm{g}}\right)$ at $30.8{ }^{\circ} \mathrm{C}^{[17]}$, none of the blends exhibited $\mathrm{T}_{\mathrm{g}}$, possibly indicating a decreased interaction between starch and HBP in the TPS.

The $\mathrm{T}_{\mathrm{m}}$ of the blends (Table 2 and Figure $3 \mathrm{a}$ ) are lower than that of $\operatorname{LDPE}\left(114.1^{\circ} \mathrm{C}\right)^{[11]}$, which is possibly due to the
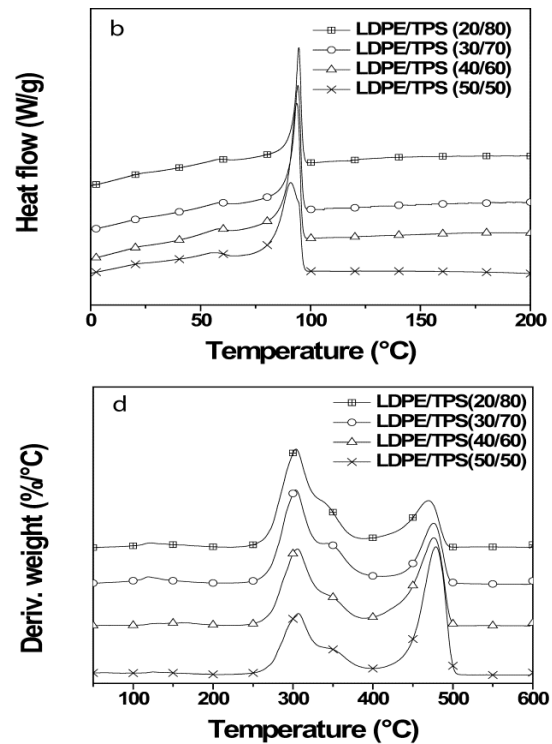

Figure 3. Thermograms showing (a) Endothermic process (DSC); (b) Exothermic process (DSC); (c) Weight vs temperature (TGA); and (d) Deriv. weight vs temperature (TGA). 
plasticizing effect of HBP. $\Delta \mathrm{H}_{\mathrm{m}}$ of the blends (Table 2) are lower than that of LDPE $(91.5 \mathrm{~J} / \mathrm{g})^{[1]}$. This is an indication that the crystallization process of LDPE is seriously affected by the presence of TPS. The $T_{m}$ values of the materials obtained in this study are similar to those found to LDPE- $g$-MA/TPS blends ${ }^{[17]}$. Therefore, the grafted MA in these materials did not affect the $\mathrm{T}_{\mathrm{m}} \cdot \Delta \mathrm{H}_{\mathrm{m}}$ increased with the LDPE amount, meaning that in the same sense the crystallinity degree of the blends was augmented. The same behavior was also observed for LDPE- $g$-MA/TPS blends prepared with the same proportions of TPS, except for that with the proportion of $50 / 50$ with the $\mathrm{T}_{\mathrm{m}}$ value of $25.70^{\circ} \mathrm{C}$, which was assigned to different packaging ${ }^{[17]}$. Despite that, the results of $\mathrm{T}_{\mathrm{m}}$ obtained in this study are comparable with those reported for LDPE- $g$-MA/TPS blends $(90.7-96.7)^{[17]}$. The $\mathrm{T}_{c}$ of the LDPE $\left(89.8^{\circ} \mathrm{C}\right)^{[11]}$ was lower than those of the blends, which is an indication that the crystallization process occurs easier for the blends than for LDPE. This behavior is attributed to the presence of TPS. The LDPE/TPS (50/50) blend with the lowest $T$ presented more difficulty to crystalize than other blends. This is related with the highest amount of TPS employed. The same behavior was also observed for LDPE- $g$-MA/TPS $(50 / 50)$ blends ${ }^{[17]}$. The values of $\mathrm{T}_{\mathrm{m}}$ obtained in this study are comparable with those obtained for LDPE- $g$-MA/TPS blends with the same proportions of $\mathrm{TPS}^{[17]}$. The crystallization enthalphy $\left(\Delta \mathrm{H}_{\mathrm{c}}\right)$ follows the same trend as $\Delta \mathrm{H}_{\mathrm{m}}$. The reduction in $\mathrm{T}_{\mathrm{m}}, \Delta \mathrm{H}_{\mathrm{m}}$ and $\Delta \mathrm{H}_{\mathrm{c}}$ of the LDPE have also been observed for LDPE/corn starch blends ${ }^{[14]}$. The $\Delta \mathrm{H}_{\mathrm{m}}$ values of the LDPE/TPS are similar to those reported for LDPE-g-MA/TPS blends ${ }^{[17]}$.

The results obtained by DSC analysis allow us to conclude that the presence of TPS affects the crystallization process of LDPE. Another important aspect is that the TPS does not act as a nucleating agent for LDPE (it would increase its degree of crystallinity), since $\Delta \mathrm{H}_{\mathrm{m}}$ of LDPE in the LDPE/TPS blends was lower than that of the proportional fraction of neat LDPE (it is an indication of reduction of crystallinity) and it did not increase with the TPS content.

TGA thermograms of the blends (Figures $3 \mathrm{c}$ and $3 \mathrm{~d}$ ) show that the first visible change occurs around $100^{\circ} \mathrm{C}$, where a small amount of water was evaporated from TPS. The HBP and starch present in the TPS can absorb water; in case of HBP, it occurs during its synthesis and in case of starch it can happen during the storage. This weight loss appears in all blends. The thermal decomposition of the TPS $\left(\mathrm{T}_{\mathrm{d} 1}\right)$ occurs at $302.3^{\circ} \mathrm{C}^{[17]}$. This was observed for all blends and it was reduced with the TPS content. The second thermal decomposition $\left(\mathrm{T}_{\mathrm{d} 2}\right)$ appears about $340{ }^{\circ} \mathrm{C}$ and is associated with HBP employed as a plasticizer for $\operatorname{starch}^{[7,17]}$.

The decomposition temperature of LDPE is $469.7^{\circ} \mathrm{C}^{[11]}$. Therefore, the third thermal decomposition of the blends above $470{ }^{\circ} \mathrm{C}$ is assigned to $\operatorname{LDPE}\left(\mathrm{T}_{\mathrm{d} 3}\right)$. The $\mathrm{T}_{\mathrm{d}}$ values of the blends are summarized in Table 2 . The $\mathrm{T}_{\mathrm{d}}$ of starch varied between 299.4 and $307.7^{\circ} \mathrm{C}$, while between 338.5 and 348.4 there are $\mathrm{T}_{\mathrm{d}}$ of $\mathrm{HBP}$, and between 470.0 and $478.3^{\circ} \mathrm{C}$ those for LDPE (Table 2). However, no characteristic pattern is present, since all the values are very close. This behavior is attributed to rearrangement that possibly occurred during the processing of the blends. Slightly enhanced thermal stability of the blends with increasing amount of LDPE was also observed. This means that LDPE elevates the thermal stability of the blends due to its high thermal stability. It has been demonstrated that the introduction of the high molecular weight material such as LDPE, induces a gradual increase in the initial decomposition temperature ${ }^{[18]}$.

The same thermal behavior as exhibited for the blends in this study was seen for LDPE/plasticized starch blends, where a $\mathrm{T}_{\mathrm{d}}$ was observed for TPS $\left(300^{\circ} \mathrm{C}\right)$ and $\mathrm{LDPE}$ (around $\left.400{ }^{\circ} \mathrm{C}\right)^{[1]}$. Furthermore, similar results were obtained by Sailaja et al. for blends of LDPE and tapioca $\operatorname{starch}^{[10]}$. In another study, the same results on thermal stability were observed for LDPE- $g$-MA/TPS blends, obtained with the same proportions of TPS (three weight losses assigned to TPS, HBP and LDPE- $g$-MA) ${ }^{[17]}$.

XRD diffractograms are presented in Figure 4. The TPS exhibits three peaks, which appear at $2 \theta=15^{\circ}, 17.5^{\circ}$ and $23^{\circ}$. The presence of these peaks in the TPS is due to the A type crystallinity of the tapioca $\operatorname{starch}^{[17]}$. In the blends, the intensity of the peak at $2 \theta=17.5^{\circ}$ increased slightly with increasing TPS content. This behavior indicates that during the processing of the blends the TPS crystallinity was modified and starch granules were restructured, possibly

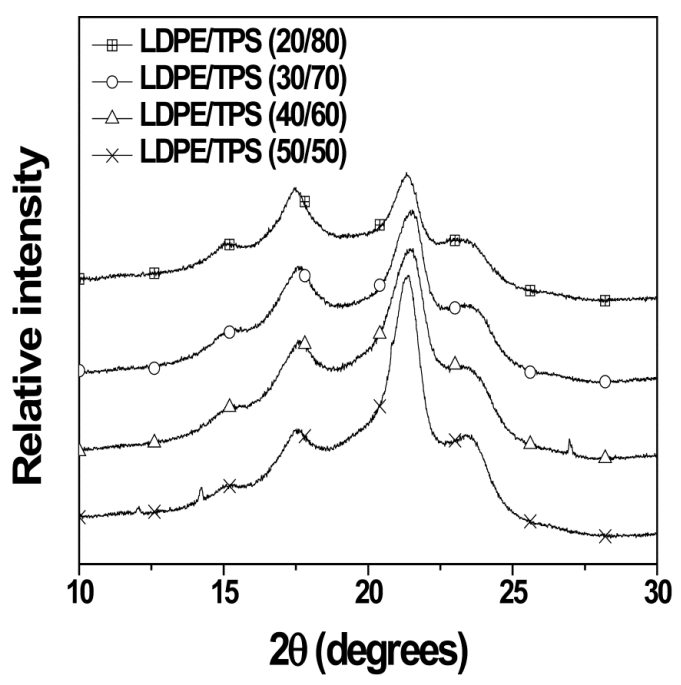

Figure 4. XRD difractograms of the LDPE/TPS blends.

Table 2. Thermal properties of the LDPE/TPS blends.

\begin{tabular}{cccccccc}
\hline $\begin{array}{c}\text { LDPE/TPS } \\
\text { blends }\end{array}$ & $\begin{array}{c}\mathbf{T}_{\mathrm{m}} \\
\left({ }^{\circ} \mathbf{C}\right)\end{array}$ & $\begin{array}{c}\Delta \mathbf{H}_{\mathrm{m}} \\
(\mathbf{J} / \mathbf{g})\end{array}$ & $\begin{array}{c}\mathbf{T}_{\mathbf{c}} \\
\left({ }^{\circ} \mathbf{C}\right)\end{array}$ & $\begin{array}{c}\Delta \mathbf{H}_{\mathbf{c}} \\
(\mathbf{J} / \mathbf{g})\end{array}$ & $\begin{array}{c}\mathbf{T}_{\mathbf{d} 1} \\
\left({ }^{\circ} \mathbf{C}\right)\end{array}$ & $\begin{array}{c}\mathbf{T}_{\mathbf{d} 2} \\
\left({ }^{\circ} \mathbf{C}\right)\end{array}$ & $\begin{array}{c}\mathbf{T}_{\mathrm{d} 3} \\
\left({ }^{\circ} \mathbf{C}\right)\end{array}$ \\
\hline $20 / 80$ & 108.9 & 14.84 & 94.7 & 17.04 & 304.0 & 338.5 & 470.0 \\
$30 / 70$ & 109.7 & 17.55 & 94.3 & 23.13 & 303.1 & 345.6 & 475.6 \\
$40 / 60$ & 110.7 & 25.90 & 93.8 & 29.62 & 304.9 & 344.9 & 475.6 \\
$50 / 50$ & 112.0 & 30.70 & 91.1 & 30.02 & 307.7 & 348.4 & 478.4 \\
\hline
\end{tabular}


due to rupture and formation of new interactions between starch and HBP. This confirms the rearrangement of TPS in the LDPE/TPS blends. The same reduction in intensity of this peak was observed for LDPE- $g$-MA/TPS blends ${ }^{[17]}$.

Another peak is observed at $2 \theta=21.5^{\circ}$, which increases its intensity as the LDPE content is enhanced. This is attributed to the crystalline regions of LDPE, because this peak is characteristic of $\mathrm{LDPE}^{[19]}$ and was not observed for TPS. It is associated with a orthorhombic unit cell[ ${ }^{17,20]}$. These results are comparable with the results obtained by DSC analysis, where the LDPE degree of crystallinity was reduced with the TPS content. The difractograms obtained in this study are very similar to those of the LDPE-g-MA/TPS blends with the same proportions of TPS, since a reduction of peak at $2 \theta=17.5^{\circ}$ with increasing TPS content and an enhanced intensity of peak at $21.5^{\circ}$ was observed in correlation with the LDPE content.

The apparent viscosity $(\eta)$ of the blends is shown in Figure 5. It has been noted that as the shear rate increases, the samples exhibit a decrease in viscosity (shear thinning) caused by dissociation of hydrogen bonding or chain disentanglement ${ }^{[2]}$. At shear rate of $10^{-1} \mathrm{~s}^{-1}$, the LDPE/TPS $(20 / 80),(30 / 70)$, and $(40 / 60)$ blends reduced the viscosity with the TPS content. The LDPE/TPS (50/50), however, did not follow the same behavior and this could be attributed to the lowest amount of HBP present in the TPS or interactions between the macromolecules of HBP. The viscosity values of the LDPE/TPS (40/60) and (50/50) were very similar in the range of shear rate between $10^{-1}$ and $10^{0} \mathrm{~s}^{-1}$. This behavior was possibly due to a rearrangement of starch granules, since these samples were prepared with higher LDPE amounts than other blends. The viscosity of the LDPE/TPS blends at a shear rate of $10^{-1} \mathrm{~s}^{-1}$ was higher than that exhibited by TPS (1328 Pa.s $)^{[17]}$, but lower than that of LDPE (94.85 Pa.s $)^{[11]}$. Therefore the presence of the TPS reduces the viscosity of the LDPE.

LDPE/TPS blends exhibited the same rheological behavior (pseudoplastic) and comparable viscosity values with those obtained to the LDPE- $g$-MA/TPS blends ${ }^{[17]}$. Furthermore, they did not show any trend with the proportion of the TPS employed for the preparation of the blends.

Figure 6 shows SEM micrographs of the LDPE/TPS blends. Starch granules within two phases and a rough surface were observed on all micrographs. This is an indication that these blends are incompatible, which was expected, since starch is hydrophilic and LDPE is hydrophobic. The same was observed for LDPE- $g$-MA/TPS blends, which was associated with weak interactions between LDPE- $g$-MA and TPS ${ }^{[17]}$. The TPS also exhibited starch granules without disruption after the plastization process ${ }^{[17]}$.

According to SEM micrographs, TPS was not equally dispersed in LDPE, since the $40 / 60$ blend presented a smoother surface than other blends. Therefore, this particular blend exhibited the best dispersion of starch. This phenomenon has been ascribed to the weak interfacial adhesion between TPS and LDPE ${ }^{[21]}$.

The mechanical properties of the blends were also investigated in correlation to the TPS content. Young's modulus and tensile strength were reduced as the TPS content decreased, but the elongation at break increased (Table 3). As TPS is

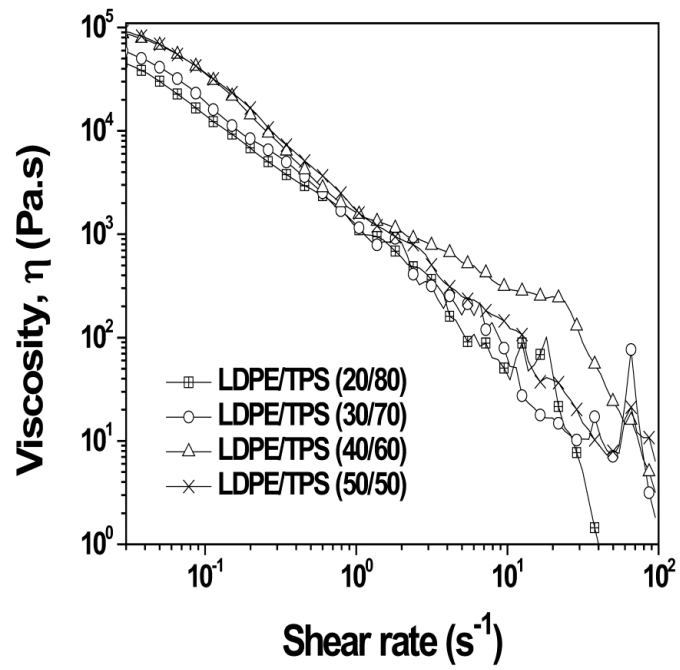

Figure 5. Viscosity vs shear rate of the LDPE/TPS blends.

Table 3. Tensile properties of the LDPE/TPS blends.

\begin{tabular}{cccc}
\hline $\begin{array}{c}\text { LDPE/TPS } \\
\text { blends }\end{array}$ & $\begin{array}{c}\text { Young's } \\
\text { modulus } \\
\text { (MPa) }\end{array}$ & $\begin{array}{c}\text { Tensile } \\
\text { strenght } \\
\text { (MPa) }\end{array}$ & $\begin{array}{c}\text { Elongation at } \\
\text { break (\%) }\end{array}$ \\
\hline $20 / 80$ & $499.0 \pm 11.8$ & $99.18 \pm 2.35$ & $3.12 \pm 0.23$ \\
$30 / 70$ & $469.6 \pm 12.3$ & $77.91 \pm 2.12$ & $3.58 \pm 0.14$ \\
$40 / 60$ & $407.4 \pm 55.7$ & $70.46 \pm 3.23$ & $3.96 \pm 0.10$ \\
$50 / 50$ & $321.4 \pm 10.0$ & $67.36 \pm 4.35$ & $4.98 \pm 0.10$ \\
\hline
\end{tabular}

a rigid and fragile material, by adding LDPE, it confers ductility reducing the Young's modulus and tensile strength, but increasing the elongation at break (Table 3). All the blends showed a significantly higher Young's modulus than neat LDPE $(92 \mathrm{MPa})^{[11]}$. The same behavior was reported on for LDPE/starch plasticized with glycerol ${ }^{[1]}$. These are unusual results considering the high levels of immiscibility between LDPE and TPS. Some authors have found that compression during crystallization, exerted by a crystalline matrix, on an amorphous dispersed phase can result in good interfacial contact and a higher Young's modulus ${ }^{[1,22]}$. In this study, Young's modulus were higher than those obtained for the LDPE/starch blends plasticized with glycerol, whose values were between 44.0 and $66.2 \mathrm{MPa}^{[1]}$. In another study, Young's modulus values of LDPE/starch blends were between 240 and $290 \mathrm{MPa}$ and increased with the starch content $(30,40 \text { and } 50 \mathrm{wt} \%)^{[14]}$. This behavior was ascribed to TPS acting as filler for LDPE. Another hypothetical reason is that HBP migrated from TPS during the processing of the blends and this possibly induced a rearrangement of starch granules, leaving the starch granules without plasticization.

In the LDPE- $g$-MA/TPS blends, high values of Young's modulus (between 224.1 and $468.1 \mathrm{MPa}$ ) were also observed; they enhanced with increasing the TPS content of the blends ${ }^{[17]}$.

The materials obtained in this study exhibited higher Young's modulus and tensile strength, but lower elongation at break than those obtained for the LDPE- $g$-MA/TPS blends with the same proportions of TPS ${ }^{[17]}$. It is important to note that the LDPE's value of Young's modulus is similar to LDPE- $g$-MA (93.58 MPa). Therefore, it was expected that 

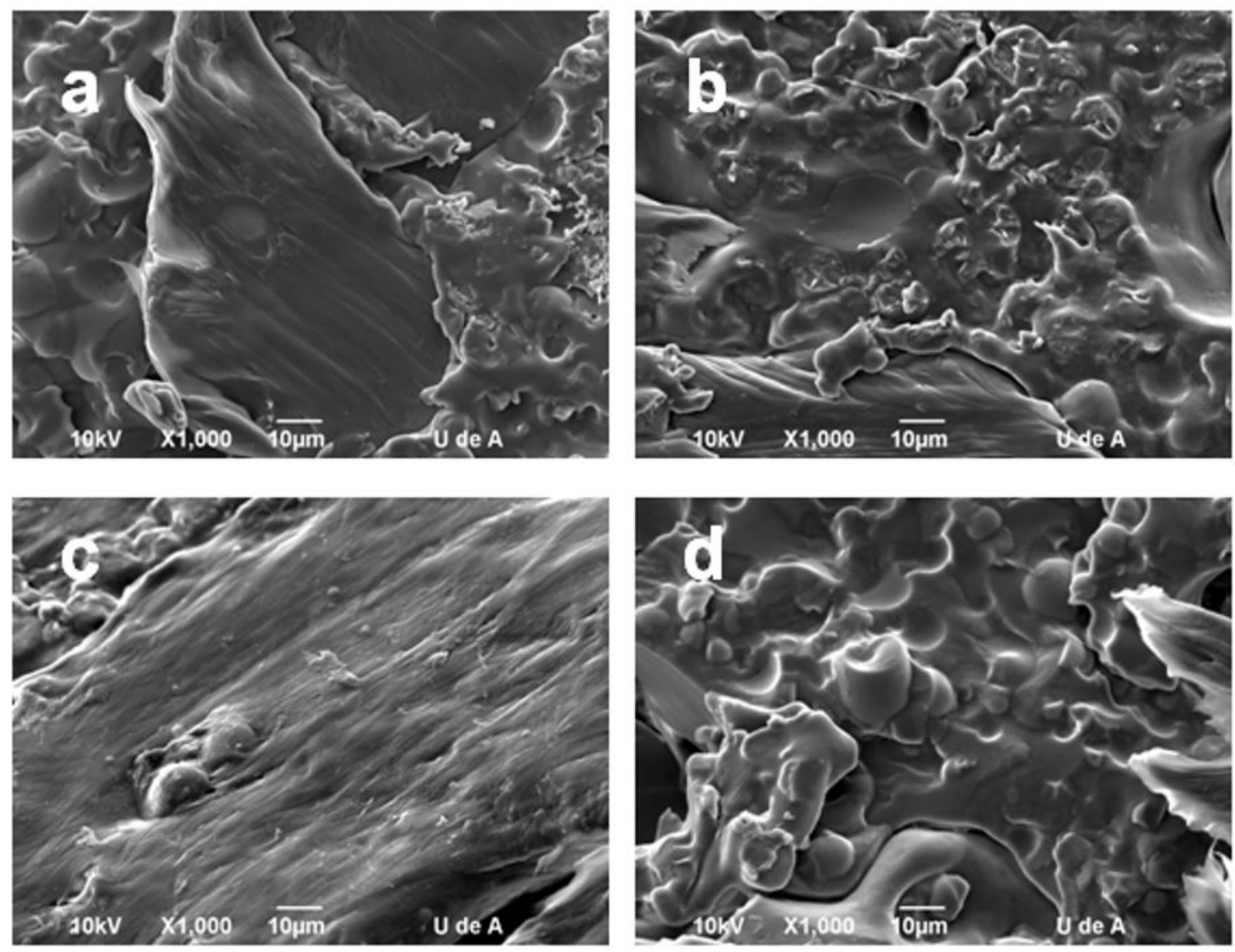

Figure 6. SEM micrographs of the LDPE/TPS blends (a) 20/80; (b) 30/70; (c) 40/60; and (d) 50/50.

the Young's modulus and tensile strength of these materials, obtained with the same proportion of TPS, would be almost equal. However, this was not the case, probably due to the fact that during the processing of these materials a structural rearrangement of TPS occurred, related to rupture and formation of the interaction between starch and HBP or interaction between macromolecules of HBP.

The lack of adhesion between LDPE and starch, seen on the SEM micrographs of fractured surfaces, indicates a poor interfacial interaction and could explain the decrease in the mechanical properties following the addition of LDPE.

\section{Conclusions}

In this study, LDPE/TPS blends were prepared. Using HBP as a plasticizer for tapioca starch makes an important contribution to the study of LDPE/TPS blends. According to the results, HBP induced a structural rearrangement of the LDPE/TPS blends. Furthermore, the presence of HBP in TPS reduced the viscosity of the LDPE/TPS blends, which was lower than that of the neat LDPE. The $T_{m}$ and $T_{c}$ values were practically the same, without significant changes, for all the LDPE/TPS blends. The LDPE/TPS blends crystalized easier than LDPE. The A type crystallinity in the blends was reduced. The thermal stability of the mixtures showed no significant changes and it did not exhibit dependence on the composition of the LDPE/TPS blends. All blends exhibited a shear thinning behavior. SEM analysis showed the presence of the granular structure of starch for all the
LDPE/TPS blends. All the blends exhibited a significantly higher Young's modulus than neat LDPE. The thermal and rheological properties of the LDPE/TPS blends were comparable with those of LDPE- $g$-MA/TPS blends prepared with the same proportions of TPS ${ }^{[17]}$.

\section{References}

1. Rodriguez-Gonzalez, F. J., Ramsay, B. A., \& Favis, B. D. (2003). High performance LDPE/thermoplastic starch blends: a sustainable alternative to pure polyethylene. Polymer, 44(5), 1517-1526. http://dx.doi.org/10.1016/S0032-3861(02)00907-2.

2. Da Róz, A., Carvalho, A., Gandini, I. A., \& Curvelo, A. (2006). The effect of plasticizers on thermoplastic starch compositions obtained by melt processing. Carbohydrate Polymers, 63(3), 417-424. http://dx.doi.org/10.1016/j.carbpol.2005.09.017.

3. Chillo, S., Flores, S., Mastromatteo, M., Conte, A., Gerschenson, L., \& Del Nobile, M. A. (2008). Influence of glycerol and chitosan on tapioca starch-based edible film properties. Journal of Food Engineering, 88(2), 159-168. http://dx.doi. org/10.1016/j.jfoodeng.2008.02.002.

4. Ma, X. F., Yu, J. G., \& Wan, J. J. (2006). Urea and ethanolamine as a mixed plasticizer for thermoplastic starch. Carbohydrate Polymers, 64(2), 267-273. http://dx.doi.org/10.1016/j. carbpol.2005.11.042

5. Yang, J., Yu, J., \& Ma, X. (2006). Study on the properties of ethylenebisformamide and sorbitol plasticized corn starch (ESPTPS). Carbohydrate Polymers, 66(1), 110-116. http:// dx.doi.org/10.1016/j.carbpol.2006.02.029.

6. Murillo, E. A., Cardona, A., \& López, B. L. (2011). Rheological behavior in the molten state and solution of hyperbranched 
polyester of fourth and fifth generation. Journal of Applied Polymer Science, 119(2), 929-935. http://dx.doi.org/10.1002/ app.32774.

7. Murillo, E. A., Vallejo, P. P., \& López, B. L. (2010). Characterization of hydroxylated hyperbranched polyesters of fourth and fifth generation. E-Polymers, 120(1), 1-12. http:// dx.doi.org/10.1515/epoly.2010.10.1.1347.

8. Murillo, E. A., Vallejo, P. P., Sierra, L., \& López, B. L. (2009) Characterization of hyperbranched polyol polyesters based on 2,2-bis (methylol propionic acid) and pentaerythritol. Journal of Applied Polymer Science, 112(1), 200-207. http://dx.doi. org/10.1002/app.29397.

9. Murillo, E. A., Vallejo, P. P., \& López, B. L. (2010). Synthesis and characterization of hyperbranched alkyd resins based on tall oil fatty acids. Progress in Organic Coatings, 69(3), 235240. http://dx.doi.org/10.1016/j.porgcoat.2010.04.018.

10. Sailaja, R. R. N., \& Seetharamu, S. (2008). Itaconic acid grafted - LDPE as compatibilizer for LDPE - plasticized Tapioca starch blends. Reactive \& Functional Polymers, 68(4), 831-841. http://dx.doi.org/10.1016/j.reactfunctpolym.2007.12.003.

11. Guzmán, M., \& Murillo, E. A. (2014). Funcionalización de polietileno de baja densidad con anhídrido maleico en estado fundido. Polímeros: Ciência e Tecnologia, 24(2), 162-169. http://dx.doi.org/10.4322/polimeros.2014.034.

12. St-Pierre, N., Favis, B. D., Ramsay, B. A., Ramsay, J. A., \& Verhoogt, H. (1997). Processing and characterization of thermoplastic starch/polyethylene blends. Polymer, 38(3), 647-655. http://dx.doi.org/10.1016/S0032-3861(97)81176-7.

13. Halley, P. J., Truss, R. W., Markotsis, M. G., Chaleat, C., Russo, M., Sargent, A. L., Tan, I., \& Sopade, P. A. (2007). Review of biodegradable thermoplastic starch polymers. ACS Symposium Series, 978, 287-300. http://dx.doi.org/10.1021/bk-2007-0978. ch024.

14. Pedroso, A., \& Rosa, D. (2005). Mechanical, thermal and morphological characterization of recycled LDPE/corn starch blends. Carbohydrate Polymers, 59(1), 1-9. http://dx.doi org/10.1016/j.carbpol.2004.08.018.

15. Ning, W., Jiugao, Y., Xiaofei, M., \& Ying, W. (2007). The influence of citric acid on the properties of thermoplastic starch linear low-density polyethylene blends. Carbohydrate Polymers, 67(3), 446-453. http://dx.doi.org/10.1016/j.carbpol.2006.06.014.

16. Garg, S., \& Jana, A. K. (2007). Studies on the properties and characteristics of starch-LDPE blend films using cross-linked, glycerol modified, cross-linked and glycerol modified starch. European Polymer Journal, 43(9), 3976-3987. http://dx.doi. org/10.1016/j.eurpolymj.2007.06.030.

17. Guzmán, M., \& Murillo, E. A. (2015). The properties of blends of maleic - anhydride - grafted polyethylene and thermoplastic starch using hyperbranched polyester polyol as a plasticizer. Polymer Engineering and Science, 55(11), 2526-2533. http:// dx.doi.org/10.1002/pen.24143.

18. Zaky, M. T., \& Mohamed, N. H. (2010). Influence of lowdensity polyethylene on the thermal characteristics and crystallinity of high melting point macro- and micro-crystalline waxes. Thermochimica Acta, 499(1-2), 79-84. http://dx.doi. org/10.1016/j.tca.2009.11.005.

19. Pushpadass, H. A., Bhandari, P., \& Hanna, M. A. (2010). Effects of LDPE and glycerol contents and compounding on the microstructure and properties of starch composite films. Carbohydrate Polymers, 82(4), 1082-1089. http://dx.doi. org/10.1016/j.carbpol.2010.06.032.

20. Mandani, M. (2010). Structure, optical and thermal decomposition characters of LDPE graft copolymers synthesized by gamma irradiation. Materials Science, 33, 65-73. http://dx.doi. org/10.1016/j.cap.2010.06.021.

21. Ning, W., Jiugao, Y., Xiaofei, M., \& Chunmei, H. (2007). High performance modified thermoplastic starch/linear lowdensity polyethylene blends in one-step extrusion. Polymer Composites, 28(1), 89-97. http://dx.doi.org/10.1002/pc.20266.

22. Leclair, A., \& Favis, B. D. (1996). The role of interfacial contact in immiscible binary polymer blends and its influence on mechanical properties. Polymer, 37(21), 4723-4728. http:// dx.doi.org/10.1016/S0032-3861(96)00319-9.

Received: Dec. 10, 2015

Revised: Apr. 12, 2016

Accepted: May 20, 2016 